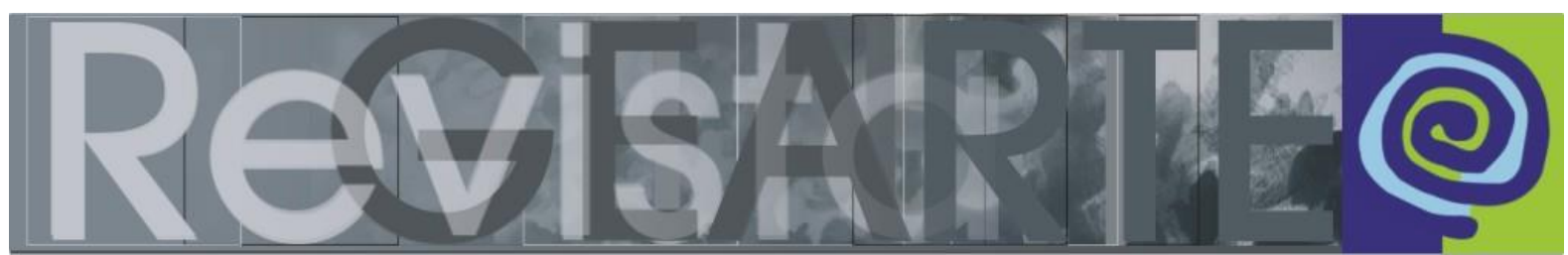

ISSN 2357-9854

\title{
O corpo que joga, ginga e dança: a Capoeira Angola na arte-educação
}

\author{
Judivânia Maria Nunes Rodrigues (Universidade do Estado \\ do Rio de Janeiro - UERJ, Rio de Janeiro/RJ, Brasil)
}

\begin{abstract}
RESUMO - O corpo que joga, ginga e dança: a Capoeira Angola na arte-educação - A Capoeira Angola, herança africana, criação afro-brasileira, é uma prática artística e cultural em permanente construção que materializa-se em imagens de diálogos corporais, filosóficos e espirituais. Tem sua criação no regime escravocrata brasileiro, período de dor e sofrimento, resistindo com corpos que se movem no incessante jogo de viver. Na contemporaneidade, continua como espaço político de resistência, mas também como manifestação que ressalta a beleza plástica de corpos brincantes. $O$ que faz o corpo na Capoeira Angola? Essa é uma prática artística? Como é possível ensinar e aprender a partir do corpo? Nesta perspectiva, usada como instrumento de arte-educação na Comunidade do Monte Serrat, em Florianópolis-SC, investigo formas de ensino e aprendizagem através do corpo e, por meio da linguagem fotográfica, produzimos a imagética que expressa a interação e a mediação a partir da experiência, o que nomeei de "Retratos de Movimentos".
\end{abstract}

PALAVRAS-CHAVE

Arte-educação. Capoeira Angola. Corpo. Retratos de Movimentos.

ABSTRACT - The body that plays, ginga and dances: the Angola Capoeira in art education Capoeira Angola, an african heritage, an Afro-Brazilian creation, is an artistic and cultural practice in permanent construction, that is materialized in images of corporal, philosophical and spiritual dialogues. It has its creation in the Brazilian slave regime, period of pain and suffering, resisting with bodies that move in the incessant game of live. In contemporaneity, it continues as a political space of resistance, but also as a manifestation that emphasizes the plastic beauty of playful bodies. What does the body do in Capoeira Angola? Is this an artistic practice? How can you teach and learn through the body? In this perspective, used as an instrument of art-education in the community of Monte Serrat, in Florianópolis-SC, I investigate ways of teaching and learning through the body and, using the photographic language, we produce the imagery that expresses the interaction and the mediation from that experience, what I named "Portraits of Movements".

KEYWORDS

Art-education. Capoeira Angola. Body. Portraits of Movements.

\section{Introdução}

Definir o que o corpo faz na prática da Capoeira Angola é, como o próprio movimento, fugaz, como se ora jogássemos ora gingássemos ou ainda dançássemos, como uma "grande brincadeira" com o corpo, uma improvisação, mesmo que se trate de movimentos treinados, a partir dos quais se experimentam os limites, avanços, transgressões, sensações, situações desafiadoras e as possibilidades de ações, de movimentos. Os possíveis movimentos manifestos pelo nosso corpo, quando não 
limitado ao mover-se de forma convencional, quando ousamos experimentar o brincar corporalmente com o outro.

Como capoeirista/artista ${ }^{1}$, educadora e pesquisadora, investigo a prática da Capoeira Angola no campo da arte-educação como uma atividade lúdica, cultural e artística, oriunda da cultura popular, que possibilita aprender e ensinar a partir do corpo. Um jogo de perguntas e respostas corporais, no qual a expressão se manifesta de forma singular para cada jogador. Exibe-se a singularidade dos corpos, que carregam e emanam energia interior, o que podemos chamar de espiritualidade, ou também, de valores e princípios que, nesse contato corpo a corpo com o outro, nos colocam em estado de estesia, mobilizando sensorialmente o nosso organismo para perceber o que nos cerca, e em estado de cinestesia, que diz respeito também às sensações, mas acrescentando a ideia do movimento ${ }^{2}$.

Praticante dessa arte da cultura popular há mais de vinte anos, tento entendêla a partir do meu próprio corpo e utilizá-la como linguagem artística no campo da arteeducação. Dessa maneira, procuro fugir de um dos principais problemas da educação tradicional: "la anulación del cuerpo como elemento de generación de conocimiento, como si la única parte de nuestra anatomía apta para el aprendizaje fuese la cabeza" (ARTE FACTUM, 2015) ${ }^{3}$.

Penso/sinto a Capoeira Angola em relação aos movimentos corporais como jogo, como ginga e também como dança. Acredito ser pertinente esse pensamento, pois é uma criação de descendência africana, cultura na qual a dança e o movimento corporal estão extremamente ligados aos afazeres cotidianos e coletivos. Alguns pesquisadores já trouxeram a questão da dança na capoeira, enfatizando muitas vezes a dança das zebras, o $\mathrm{N}^{\prime}$ golo ${ }^{4}$, como uma possível raiz para criação da

1 Termo que utilizo atualmente nas minhas pesquisas por considerar a Capoeira Angola como arte.

2 Cinestesia está associada a um senso espacial corporal interno e externo, sendo a dimensão externa associada ao conceito denominado peri-espaço, que seria o espaço não corporal logo em torno do corpo e que faz parte de um sistema de esquema corporal ligado à sensação do movimento" (CASTRO; GOMES, 2011).

3 Compartilhamento de dados por David sobre o Seminário de "Pedagogias corporales: no pensamos con la cabeza, pensamos con el cuerpo". Disponível em: <https://artefactumm.wordpress.com/ 2015/08/09/pedagogias-corporales-no-pensamos-con-la-cabeza-pensamos-con-el-cuerpo/>.

4 Disponível em: <http://cap-ang.blogspot.com.br/2009/11/danca-da-zebra.html>. 
capoeira. Esse olhar lançado sobre o movimento dos animais, muito presente nos movimentos corporais e danças africanas, que por muito tempo foram reprimidas no Brasil, por serem tachados como primitivos, nos moldou a tomar distância sobre nossa conexão corporal com a natureza, com os animais e com nossa própria ludicidade elemento essencial ao ser humano, principalmente na infância.

Para trazer a questão da capoeira como uma linguagem que dialoga com a dança, lembro-me de quando assisti ao filme Pina Bausch (2011), dirigido pelo cineasta alemão Win Wenders, e o quanto o mesmo me emocionou. A forma como a artista interagia com seus alunos incentivando-os a buscar o seu ser, a sua interioridade, a sua identidade, para que fosse possível expressar isso através da dança, me fez pensar sobre a minha experiência com a Capoeira Angola. A ginga da capoeira não é homogênea, pois cada um tem a sua maneira de gingar, que jamais será igual ao outro, assim como os demais movimentos. Além disso, cada jogador tem uma intensidade diferente na forma de jogar e se expressar.

As pesquisas realizadas sobre a Capoeira Angola são recentes e ainda representam um número pequeno, especialmente no campo da arte, o que me faz tomar de empréstimo, autores da área da antropologia, que falam sobre corpo e expressividade, assim como leituras relacionadas ao campo na dança, pois a minha prática como capoeirista me permite reconhecer o diálogo existente entre essas linguagens, sem perder de vista é claro, as especificidades de cada uma. Neste sentido, encontro esse diálogo com a obra de José Gil, autor que pretendo enfatizar aqui, para falar sobre corpo e movimento, na experiência de arte-educação, a partir da linguagem da Capoeira Angola e da fotografia, que desenvolvo como projeto de pesquisa de doutorado. A fotografia permeia todo o processo, dando visibilidade ao mesmo tempo ao campo da arte-educação, utilizada como metodologia no aprendizado da Capoeira Angola, e à criação de imagens que nomeei como "Retratos de Movimentos".

\section{Retratos de Movimentos: um modo de ver e sentir a Capoeira}

As lentes, através das quais podemos observar, refletir e sentir sobre a manifestação artística e cultural afro-brasileira, a qual chamamos de capoeira, são 
diferentes. As lentes de um antropólogo, de um historiador, de um artista, de um cidadão sem formação escolar, de um artista/capoeirista ou de um estrangeiro que não conhece essa manifestação, são possíveis e distintas. Trago essa reflexão devido às diversas observações e diálogos que tenho tido com praticantes e "plateia" durantes esses mais de vinte anos de experiência com a Capoeira Angola.

Seguindo esse raciocínio, parto da minha experiência como capoeirista/artista, para pensar sobre as possibilidades de experiências com a Capoeira Angola. Mesmo depois de me deparar várias vezes com as rodas de capoeira nas ruas de Recife, cidade onde cresci, aquela manifestação não me seduzia. Talvez, porque nunca tinha visto a modalidade de capoeira, a qual me atraiu desde o primeiro olhar, a Capoeira Angola, que na época, há mais de vinte anos atrás, não era tão difundida quanto a Capoeira Regional, cujas rodas são mais comumente vistas nas ruas da cidade.

Quando vi pela primeira vez a Capoeira Angola, na academia Capoeira Angola Mãe, em 1995, em Olinda-PE, aquela manifestação me tomou pelo olhar, pela beleza plástica dos corpos que se moviam naquele jogo. Na época, meu pensamento aconteceu sem nenhum tipo de reflexão sobre o que representava aquela manifestação em termos de história, de luta ou de resistência política negra, mas foi provocado pela sua exterioridade, pela sua forma tal qual ela se apresentava. Atribuo isso ao pouco acesso, ou mesmo ausência, que tínhamos, na escola, sobre a cultura africana e afro-brasileira e sobre os movimentos negros e toda a política de resistência relacionada a esse universo e a aceitação da própria capoeira enquanto arte popular. Mesmo sem informações históricas sobre a simbologia da capoeira, sobre o que estava por trás daquela representação, fui impactada por aquela manifestação, pelo seu exterior, pela pele.

Os movimentos em si instigavam-me a experimentar, a desejar saber o que sentem os corpos ao fazê-los. E ao experimentá-los pela primeira vez, em 1995, um mês depois de ter visto a Capoeira Angola na academia de Capoeira Angola Mãe, os mesmos começaram a fazer parte do meu corpo e perduram até hoje: como é comum se escutar no meio capoeirístico, "é a capoeira que te escolhe e não você a ela" (COLUMA; CHAVES, 2013, p. 176). 
Em 1995, começa minha experiência com o universo da Capoeira Angola, a qual ocupou um lugar muito significativo na minha vida, mudando por completo a minha forma de ver o mundo, de me relacionar e de me posicionar na vida: "Na experiência os elementos não estão perdidos, eles encontram-se imersos na corporalidade" (SILVA et al., 2009, p. 15). A percepção do meu corpo e do corpo do outro nesse jogo da capoeira foi uma descoberta que me possibilitou conhecer melhor a mim mesmo, a entender as relações humanas, que se mostravam agora de forma muito clara no jogo da Capoeira Angola. 'Por 'consciência do corpo' não entendemos a consciência de um órgão quando ele se faz sentir na dor ou no prazer; nem entendemos que seja a consciência das 'localizações das sensações'” (GIL, 2004, p. 01). O jogo corporal que leva à consciência do corpo é entendido como uma forma de ser e estar no mundo, assim como também uma possibilidade de se enxergar e se relacionar nesse jogo e nessa roda de capoeira, que é também a roda da vida.

\begin{abstract}
Digamos que a impregnação do pensamento pelos movimentos do corpo se opera num espaço virtual em que se actualizam ao mesmo tempo os movimentos corporais e os movimentos de pensamento. Numa imagem simples e simplificadora, diríamos que num estado de transe ou de grande intensidade de criação artística, por exemplo, quando a consciência se deixa invadir pelos movimentos do corpo, os dois elementos convergem, transformando-se, para o espaço único em que a osmose se produzirá: é no mesmo processo de actualização do movimento virtual em movimento do corpo no espaço e em movimento de pensamento, que ocorre a impregnação da consciência pelo corpo. É assim que não só a consciência devém corpo de consciência - em que os movimentos da consciência sabem do seu espaço tão imediatamente como o corpo sabe dos seus gestos (practognósias) - mas o próprio corpo se torna consciência, capaz de captar os mais ínfimos, invisíveis e inconscientes movimentos dos outros corpos. Movimentos de forças e de pequenas percepções. A consciência do corpo comporta assim dois regimes, um que resulta da transformação da consciência vigil intencional, e outro que decorre da mutação do corpo que se torna uma espécie de órgão de captação das mais finas vibrações do mundo (GIL, 2004, p. 03).
\end{abstract}

O pensamento do autor dessa citação me remete ao que sinto em relação ao aprendizado a partir da Capoeira Angola. A efemeridade dos movimentos no jogo da Capoeira Angola aponta para o que o autor chama de impregnação da consciência pelo corpo, ou seja, corpo e pensamento são um só, o sentir, o pensar e o agir estão simultaneamente acionados, não é possível pensá-los em separado, todos estão conectados. Dessa forma, a percepção corporal é bastante estimulada, o sentir o outro nas finas vibrações de que fala o autor, permitindo se relacionar com esse outro, 
improvisando com o corpo, a partir de uma base de movimentos, para responder ao outro corporalmente.

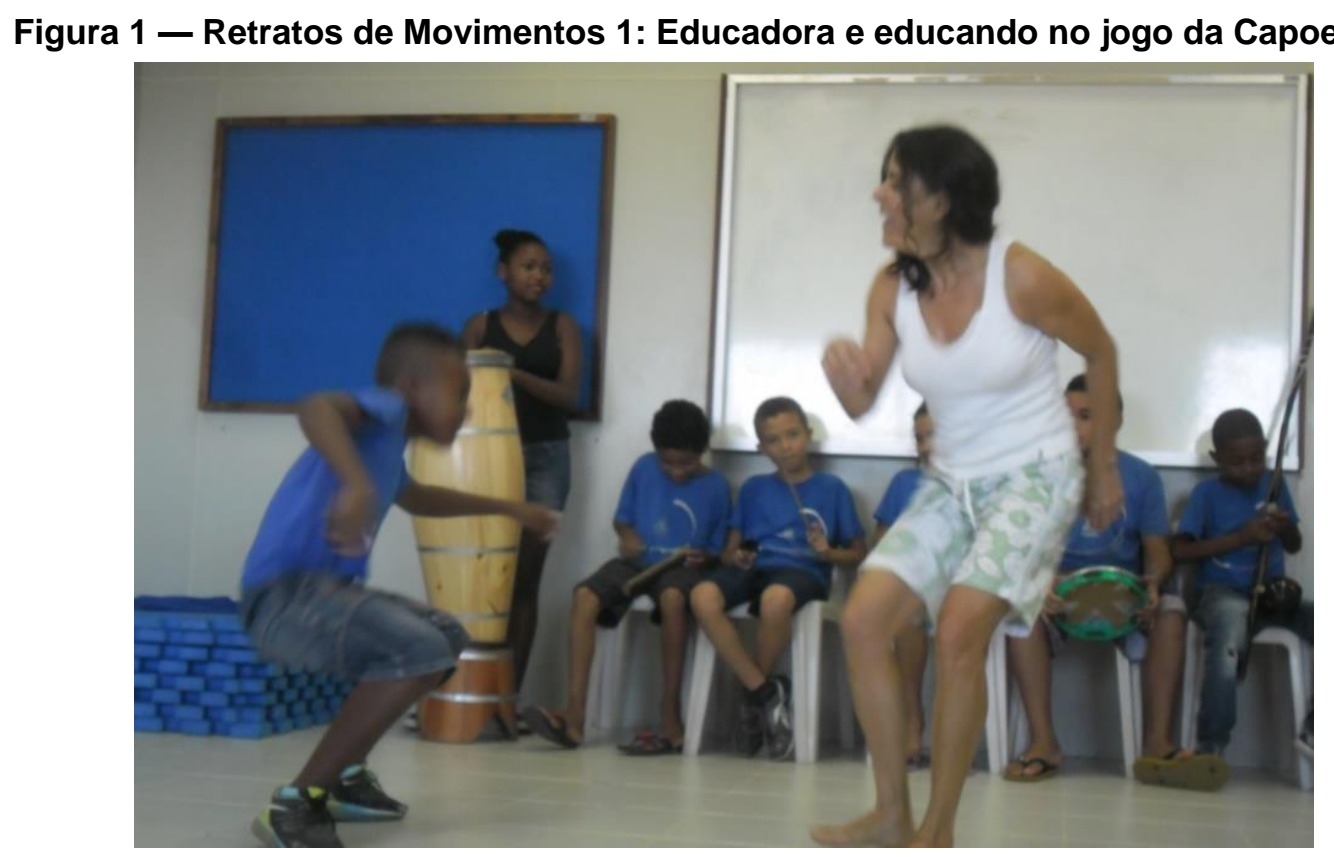

Fonte: arquivo da autora.

Como na imagem acima, onde há ginga, mas também há dança, o corpo em movimento para responder ao outro, num movimento de equilíbrio, no qual "Há duas espécies de equilíbrio corporal: o puramente mecânico, de um sistema físico; e um outro que o movimento e a consciência introduzem no corpo. O movimento dançado nasce da colaboração desses dois equilíbrios" (GIL, 2001, p.19). Uma noção complementada pelo autor quando diz que "O corpo que a dança torna instável não é um sistema mecânico. Que tem ele a mais que um corpo físico não tem? O espírito e a sua energia" (GIL, 2001, p.26).

Muitas vezes, o movimento corporal nesse jogo vem na direção da completude. Essa completude só se faz possível quando sinto a energia positiva do outro, na direção de jogar com o outro e não contra o outro. Quando essa energia é sentida, os movimentos fluem, como se pudéssemos, mesmo que por frações de segundos, ser um só corpo movente. O corpo do outro torna-se como um prolongamento do meu próprio corpo, no sentido de completude, em que é possível experimentar os desafios exigidos pelo jogo, porém de forma lúdica, o brincar com o outro, estar com o outro de 
forma prazerosa, aprendendo, emanando energia construtiva, perceptível aos nossos sentidos.

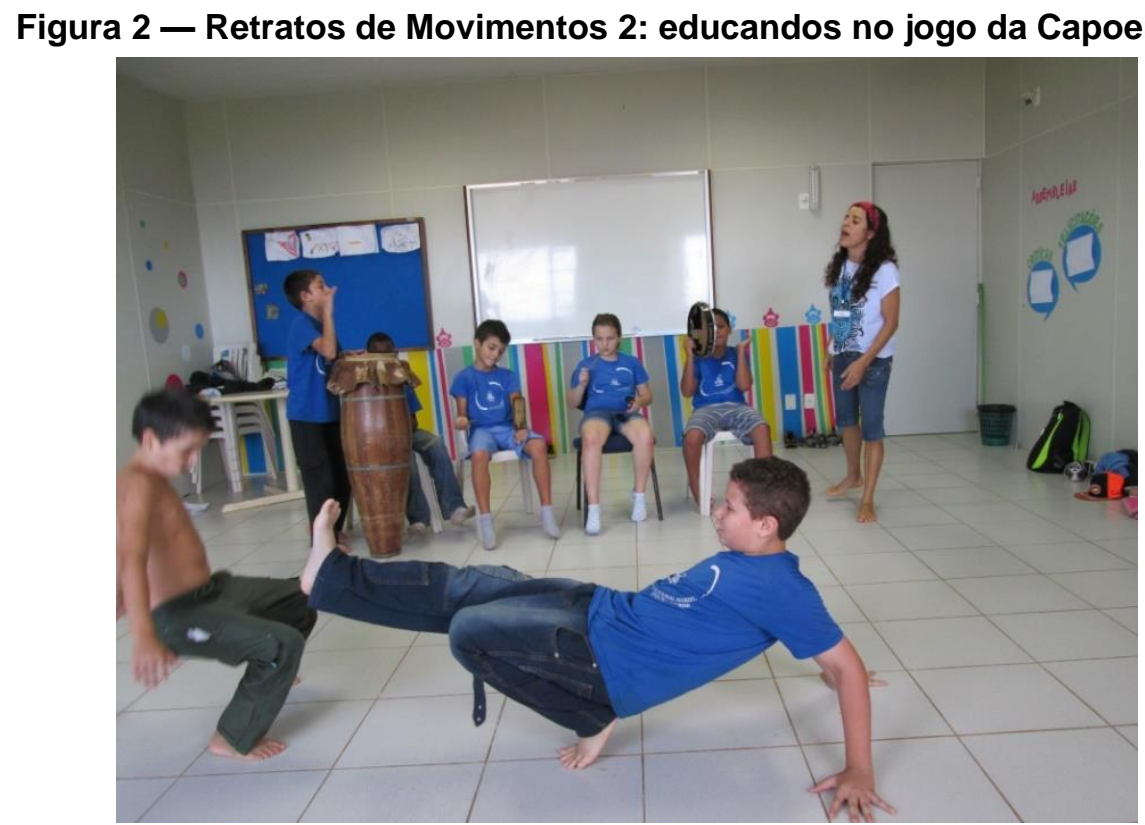

Fonte: arquivo da autora.

Figura 3-Retratos de movimentos 3: Um só corpo: a esquerda, imagem produzida no programa Photscape, a direita imagem produzida com a técnica Van Dyke, ambas a partir da fotografia
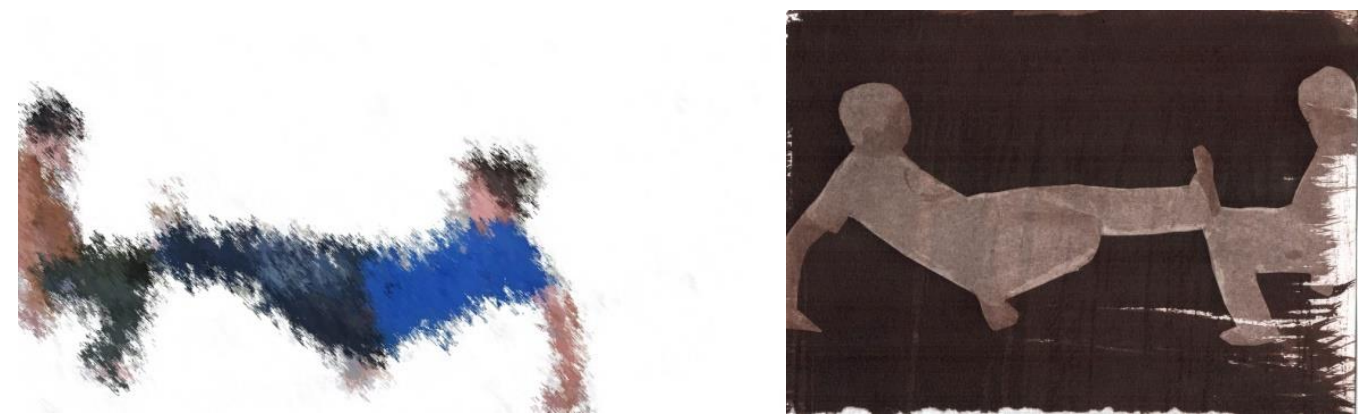

Fonte: arquivo da autora.

Nesses, e em tantos outros "Retratos de Movimentos" que estamos produzindo, os corpos se fundem em um só, a imagem nos possibilita captar essa fusão, que acontece não fisicamente, mas espiritualmente, por um breve espaço de tempo, mas suficiente para sentir o outro e acontecer a troca de energia possível nesse jogo.

Nesse mesmo percurso reflexivo, outro trabalho que me fez pensar sobre a capoeira foi o do escritor e psicanalista brasileiro Roberto Freire (1927 - 2008), criador 
da Somaterapia, uma terapia que usa a prática da Capoeira Angola como uma de suas ações. Esse trabalho me auxiliou a ver a relação entre o jogo na roda e o posicionamento na vida. A Somaterapia é, segundo seu autor, uma terapia de grupo baseada na relação entre o trabalho corporal e o uso da linguagem verbal. Foi idealizada a partir das pesquisas de seu idealizador sobre a obra de Wilhelm Reich, discípulo dissidente de Freud, sobre a crença no Anarquismo e nas pesquisas sobre corpo e emoção ${ }^{5}$.

Na época em que iniciei a capoeira, estava praticando a mesma com um grupo de pessoas que estavam fazendo a Somaterapia. Participar da terapia não era prérequisito para praticar a capoeira com o grupo, mas mesmo não tendo participado da terapia, pude através do relacionamento com as pessoas do grupo e algumas vezes com o próprio Roberto Freire, perceber o diálogo que perpassava a prática: você é na roda de capoeira o que você é na vida, e a partir disso, cabe a cada um conseguir se perceber, perceber o outro e descobrir a melhor forma de se relacionar nesse "jogo".

O jogo traz por meio do corpo, o ser de forma integral, com seus medos, desejos e atitudes que o conduzem também na vida. Não é possível não se mostrar na roda da capoeira, e uma das maiores dificuldades é realizar o jogo como prega a sua filosofia, que é o jogar com o outro e não contra o outro. A capoeira vai contra toda uma ideologia imposta pelo nosso sistema vigente que é baseado na competitividade e na individualidade.

Foram necessários muitos anos praticando a capoeira, para aos poucos ir entendendo a profundidade e a filosofia de vida que estava por trás do ser "angoleiro ou angoleira", como chamamos os praticantes da Capoeira Angola. O Mestre Pastinha, o criador da Capoeira Angola, dizia que a capoeira está pronta, não precisa de mais nada, pois ela é você, a capoeira é o que você tem dentro. Se você tem violência, ela vem em forma de violência, se você tem brincadeira e alegria ela vem

5 Verificar: <http://www.somaterapia.com.br/>; <http://pt.wikipedia.org/wiki/Somaterapia> (apesar de a Wikipédia não ser uma fonte indicada para pesquisas acadêmicas, o conteúdo sobre a Somaterapia é bastante consistente). 
dessa forma. ${ }^{6}$ Essa afirmação nos direciona para toda a subjetividade e criatividade possível de ser lançada no processo de ensino e aprendizagem da capoeira a partir da experiência de cada um. Como afirma esse velho mestre de capoeira: "cada um é cada um". Gil ao falar sobre a arte afirma que, "o trabalho do bailarino [é] como uma busca de fazer a interioridade do corpo, a confusão entre órgãos, sentimentos e afetos, [precisa] ser plena projeção no espaço, plena exterioridade desde dentro" (GIL, 2004, p. 60), o que considero ser também o que expressa o capoeirista/arista quando joga.

\section{Retratos de Movimentos: sentindo no(o) corpo (n)a experiência em arte-educação}

Os retratos de movimentos apresentados anteriormente são relatos visuais do processo de arte-educação que está sendo desenvolvido como pesquisa de doutorado, no Centro Educacional Marista Lúcia Mayvorne, na comunidade do Monte Serrat, em Florianópolis-SC, desde 2015. Deste ponto em diante do texto, irei determe, mais especificamente, em fazer a conexão entre a minha experiência pessoal como artista/capoeirista e a minha experiência profissional enquanto educadora e pesquisadora.

A Comunidade do Monte Serrat é uma comunidade afro descente, formada por escravos libertos, que na década de 1920 foram expulsos do centro da cidade pelo processo de higienização e subiram um dos morros, que fazem parte do Maciço do Morro da Cruz em Florianópolis, o Morro da Caixa, e formaram a Comunidade. Esse contexto deixa transparecer o legado africano que ali se encontra, como a presença de uma das Escolas de samba mais antigas da cidade, a Copa Lord, terreiros de candomblé, entre outras manifestações desse legado. Neste sentido, a vivência das crianças, com as quais trabalho no Centro Educacional Marista Lúcia Mayvorne, está carregada de ritmos e expressões corporais que dialogam com as práticas brincantes da cultura popular afro-brasileira, dentre elas a Capoeira Angola.

Nesta perspectiva, desenvolvo a pesquisa em arte-educação pensando na relação de diálogo entre a arte e o contexto local, a partir da minha experiência

6 Disponível em: Mestre Pastinha - entrevista 1964 por Helina Rautavaara $<$ https://www.youtube.com/watch?v=hp88iD-O7mQ>. 
enquanto capoeirista/artista. Neste contexto, de muita violência e com intenso tráfico de drogas, percebo a resistência das crianças aos processos tradicionais de educação e instauro o lúdico, a partir da Capoeira Angola, como proposta de arte e educação. Essa prática traz elementos da brincadeira para a ação educativa, e é na brincadeira, que encontro possibilidade de diálogo com os educandos, um diálogo corporal, ainda muito pouco estabelecido nos processos escolares, porém necessário, especialmente em contextos onde as crianças são submetidas ao trabalho infantil, sendo-Ihes, muitas vezes, roubado o direito ao brincar.

Pensar no nosso corpo como reflexo das experiências vividas, que precisam ser expressadas para possíveis reflexões e percepções sobre si mesmo, sobre o outro e o entorno vivenciado. Corpos impregnados de muitas sensações ou também da ausência delas. Por meio do jogo da Capoeira Angola, coloca-se o ensino e o aprendizado dos movimentos como brincadeira, como um faz de conta em relação aos golpes, no qual sempre tem que haver um espaço físico entre os dois jogadores, um fazer que é também espiritual, de respeito pelo outro, pelo espaço corpóreo do outro. Este espaço nomeei como "Do Lugar-Entre", que é sentido, experimentado no jogo, e registrado por meio da fotografia.

Bateson (2000, p.37) traz a ideia de brincadeira, exemplificando que "a dentada de brincadeira denota a mordida, mas não denota o que seria denotado pela mordida". Esse exemplo é muito coerente para se fazer uma analogia com a ideia da brincadeira no jogo da Capoeira Angola, no qual os movimentos só precisam ser mostrados e não necessariamente executados, o que muitas vezes machucaria o outro, inclusive de forma grave.

Em sua pesquisa, o autor investigou o fenômeno da brincadeira, primeiramente observando os animais e diz que "este fenômeno, o da brincadeira, só poderia ocorrer se os organismos participantes, fossem capazes de algum grau de metacomunicação, isto é, de trocarem sinais que transmitissem a mensagem isto é brincadeira" (BATESON, 2000, p.37). Na Capoeira Angola, esta mensagem é transmitida através dos golpes aplicados, os quais não precisam ser finalizados na intensidade de abater, de machucar o outro, mas de mostrar ao outro que ele corre perigo, mas que podemos transformar esse perigo em brincadeira. Como? É nesse instante que entram os 
ensinamentos do Mestre Pastinha, criador da Capoeira Angola, que sempre ensinava aos seus alunos: o bom capoeirista é aquele que consegue frear o pé e ter controle do seu próprio corpo para não machucar o outro e nem a si mesmo. Essa compreensão traz o lúdico e afasta o combate do jogo, abrindo espaço para o brincar corporalmente, exigindo a dinâmica e apresentando os desafios que fazem parte do jogo, mas explicitando as possibilidades de se relacionar em outra esfera que não necessariamente a do combate ou da competição. Essa outra esfera, a qual me referi, dialoga com o conceito de liminaridade de Turner (1967), que passa por possibilidades alternativas coletivas de se relacionar, "de criações de mundos", como uma espécie de antiestrutura, frente ao nosso sistema vigente.

O belo do jogo da Capoeira Angola se encontra na proximidade dos corpos que quase se tocam, mas abrem espaço para o outro nessa brincadeira, onde conseguem através da flexibilidade, da ginga e da mandinga ${ }^{7}$ se situarem espacialmente, num movimento que cuida de si e do outro, exibindo toda a beleza plástica de corpos brincantes. Corpos/Espíritos que se entregam ao jogo, como se não estivessem prestando atenção a mais nada, "vivendo o jogo", mas consciente do espaço circundante.

A visualidade "Do Lugar-Entre" que dialoga com a ideia da proximidade entre os corpos que descrevi anteriormente, tem sido explorada, nesta experiência de arteeducação, através da exibição e discussão com os educandos sobre a obra de dois fotógrafos, Pierre Verger e Marcel Gautherot, os quais fotografaram de forma consistente a prática da capoeira no Brasil. Proponho aos educandos que joguem e também fotografem os jogos, os corpos, na busca de capturar imagens que eles queiram expressar/criar e, imagens "Do Lugar- Entre", que nesse processo torna-se um lugar praticado sensorialmente durante o jogo, e visualmente registrado através da fotografia.

7 Segundo Dias (2009, p. 55), entre outras coisas, "[...] a mandinga ainda tem uma função estética: ela embeleza o jogo da capoeira, aparece como uma representação teatral. É a malemolência do corpo do jogador que, ao som do berimbau, traz leveza à luta, o sorriso traiçoeiro, o golpe não previsto, a brincadeira de capoeira. O jogador que sabe controlar seus movimentos, que ataca de surpresa, brinca com a falsidade. O capoeira mandingueiro só quer vadiar". Disponível em: <http://www.revistahistoria.ufba.br/2009_2/a04.pdf>. 


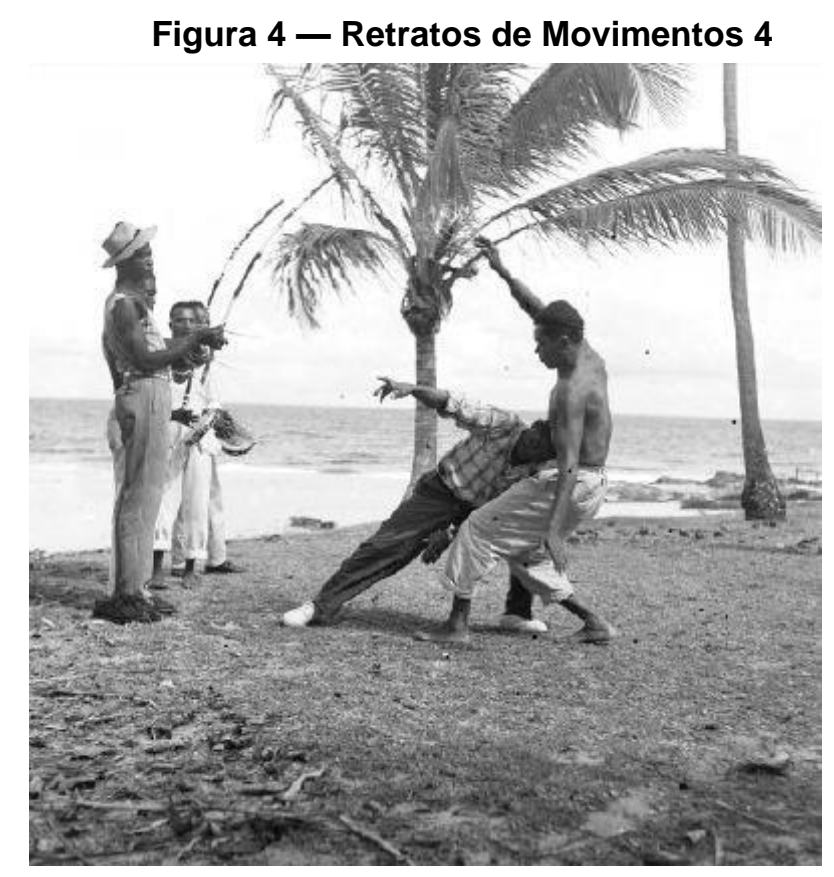

Fonte: Foto de Marcel Gautherot.

Muitas vezes, o "Lugar-Entre" é imperceptível nas imagens fotográficas, mas ele é sensorialmente experimentado no corpo, como na foto acima, em que os corpos fluem, como a ideia da brincadeira de Bateson, sem necessariamente colocar a intensidade que pode machucar o outro, exercitando isso corporalmente. Os educandos são convidados a sentir no jogo, assim como registrar visualmente esse espaço.

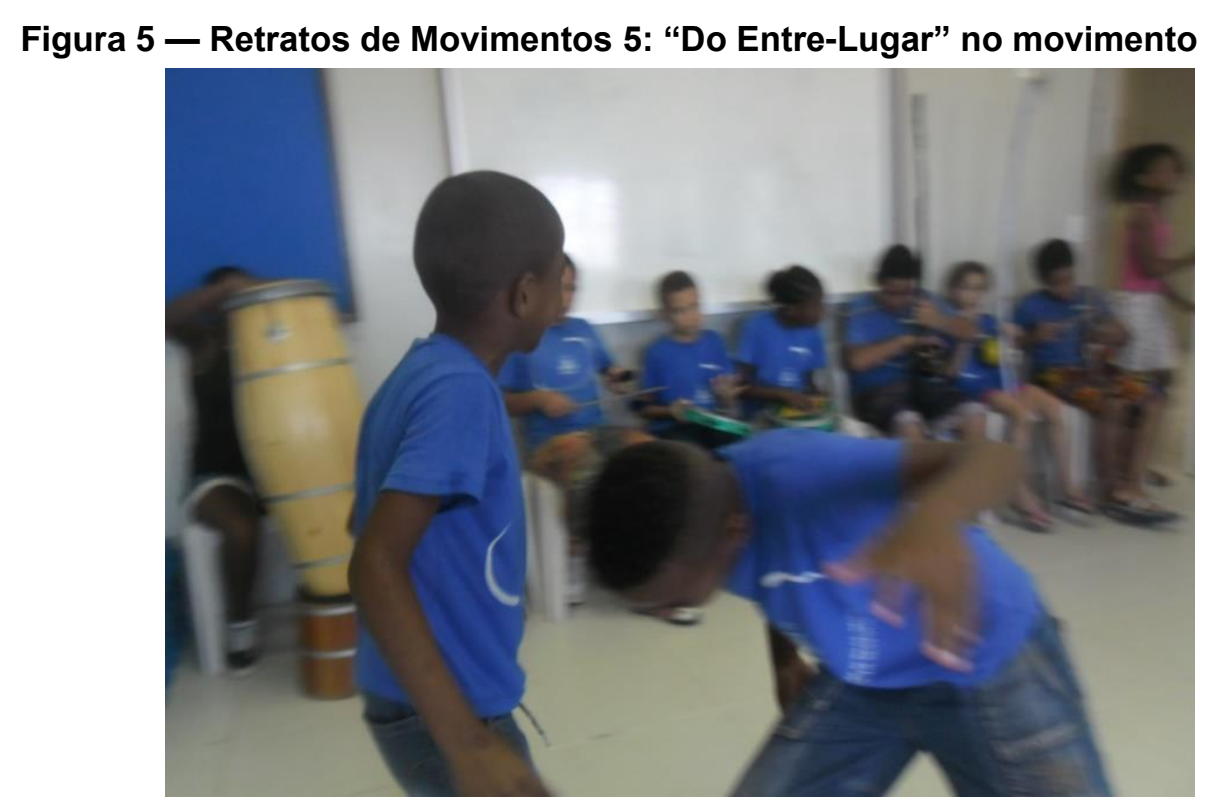

Fonte: arquivo da autora. 
Como na imagem acima, onde esse espaço torna-se visível, além de sentido corporalmente. Nesse processo, apreender e aprender através do corpo são ações constantes. O jogo da Capoeira Angola, como linguagem na arte-educação, traz o sentido ao qual Gil nos explica tão bem quando fala da dança:

\begin{abstract}
Sai deliberadamente da postura do homem comum para se colocar desde o início na dificuldade: desequilibra-se, procura as situações instáveis que produzem esse movimento da evolução da criança entre o gatinhar e o estar de pé. Repete a ação infantil, mas agora a partir do equilíbrio aprendido. E é isso que muda tudo. Notemos que esse pequeno deslocamento marca o nascimento da arte, ou pelo menos a sua possibilidade. Deixando de adoptar uma postura natural, o corpo dá-se um artifício, faz-se artificial: pode doravante tornar-se imagem, quer dizer matéria de criação de formas (GIL, 2001, p. 24).
\end{abstract}

Esse pensamento faz-se presente no corpo que expressa, corpo que diz, corpo que sente, corpo que aprende a ver a si mesmo e ao outro no jogo da Capoeira Angola, o que se estende para a vida, para além da roda de capoeira.

\title{
Considerações Finais
}

A capoeira, outrora praticada por escravos, ou mais recentemente, nos anos de 1920, por pessoas tidas como vagabundos ou desordeiros, era perseguida e marginalizada. Dessa forma, a ênfase dada pela sociedade, até mesmo nas pesquisas que abordavam o tema, era a questão da violência, da agressão, do uso das navalhas, entre outros elementos que a tornavam marginal. O caráter lúdico que sempre existiu nesse jogo, era ocultado, ou até mesmo imperceptível para a maior parte das pessoas, que não observavam profundamente essa prática artística e cultural como forma de resistência, em um período de muita dor e opressão, quando o corpo teve que se transformar em arma para sobreviver. Porém, o processo histórico dessa prática, que chega a ser hoje reconhecida como Patrimônio Cultural Imaterial Brasileiro, nos aponta para uma arte importante, um processo artístico, político e de resistência cultural.

Nesta perspectiva, a arte-educação encontra nas manifestações culturais afrobrasileiras um amplo campo de ação a ser explorado. A experiência de arte-educação ressaltada nesse artigo, como pesquisa em processo, busca contribuir para afirmação do potencial dessas manifestações, a partir da Capoeira Angola, criando, inventando 
no próprio fazer, maneiras de fazer, metodologias que possibilitem representá-la por meio da interação e da mediação realizada.

Nessa experiência, o ensinamento da Capoeira Angola se encontra no corpo, no exterior, o qual é internalizado, fazendo o movimento de fora para dentro, num processo de aprendizagem cognitiva, corporal e espiritual. A criação imagética, a partir da linguagem fotográfica, tem outro movimento, produzindo imagens de dentro para fora, internalizadas a partir do jogo, da interação sujeito-sujeito, para que seja ressaltado tanto através das imagens que buscam "um só corpo movente", como o "lugar-entre", ambos como lugar de respeito pelo espaço corpóreo do outro. O corpo, nesse processo de arte-educação, se apresenta como campo de ação por meio da interação, da experiência vivida, que traz sentido, estabelecendo coerência entre discurso e prática.

\section{Referências}

ARTE FACTUM. Pedagogias Corporales: no pensamos com la cabeza, pensamos con el cuerpo. Publicado por David em 09/08/2015. Disponível em: <https://artefactumm.wordpress.com/ 2015/08/09/pedagogias-corporales-no-pensamos-con-la-cabeza-pensamos-con-el-cuerpo/>. Acesso em: 23 jan. 2017.

BATESON, Gregory. [1954]. Uma teoria sobre brincadeira e fantasia. Cadernos IPUB, Rio de Janeiro, n. 5 , p. 35-49, 2000.

CASTRO, Thiago Gomes de; GOMES, William Barbosa. "Como sei que eu sou eu?": cinestesia e espacialidade nas conferências Husserlianas de 1907 e em pesquisas neurocognitivas. Revista da Abordagem Gestáltica, Goiânia, v.17, n.2, 123-130, jul./ dez. 2011. Disponível em: <<http://pepsic.bvsalud.org/scielo.php?script=sci_arttext\&pid=S1809-68672011000200002>. Acesso em: 25 jan. 2017.

COLUMÁ, Jorge Felipe, CHAVES, Simone Freitas. O Sagrado no Jogo de Capoeira. Textos escolhidos de cultura e arte popular, Rio de Janeiro, v.10, n.1, p.169-182, mai. 2013.

DIAS, Adriana Albert. A mandinga e a cultura malandra dos capoeiras (Salvador 1920-1925). Revista de História, v. 1, n. 2, pp. 53-59, 2009.

GIL, José. Abrir o Corpo. In: FONSECA, Tânia Mara Galli; ENGELMAN, Selda (Org.). Corpo, Arte e Clínica. Porto Alegre: Ed. UFRGS, 2004.

GIL, José. Movimento total: o corpo e a dança. Lisboa: Relógio D’Água Editoras, 2001.

SILVA, Ana Márcia et al. Corpo e experiência: para pensar as práticas corporais. In: FALCÃO, José Luiz Cirqueira; SARAIVA, Maria do Carmo (Orgs.) Práticas Corporais no Contexto Contemporâneo: (in) tensas experiências. Florianópolis: Copiart, 2009. p. 10-20.

TURNER, Victor. Betwixt and between: o período liminar nos 'ritos de passagem' In: TURNER, Victor. Floresta de símbolos: aspectos do ritual Ndembu. Niterói, RJ: EdUFF, 1967, p. 137-158. 


\section{Judivânia Maria Nunes Rodrigues}

Doutoranda do Programa de Pós-Graduação em Artes (PPGARTES) da Universidade do Estado do Rio de Janeiro (UERJ), na Área de Concentração: Arte e Cultura Contemporânea. Linha de Pesquisa: Arte, Cultura e Cognição. Orientadora: $\operatorname{Prof}^{\mathrm{a}} \mathrm{Dr}^{\mathrm{a}}$ Isabela Frade. Atua, desde 2003, no âmbito da educação não-formal, idealizando e desenvolvendo Projetos de Arte-Educação em comunidades, a partir de editais do BNDES, FUNARTE e Fundação Cultural Franklyn e Cascaes. É arte-educadora no Centro Educacional Marista Lúcia Mayvorne, na Comunidade do Monte Serrat, em Florianópolis-SC.

E-mail: rodrigues.vania@gmail.com

Currículo: http://lattes.cnpq.br/1542906044972618 